\title{
Voltage- and Ligand-Activated Inwardly Rectifying Currents in Dorsal Raphe Neurons in vitro
}

\author{
J. T. Williams, W. F. Colmers, and Z. Z. Pan \\ Vollum Institute, Oregon Health Sciences University, Portland, Oregon 97201
}

Intracellular recordings were made from neurons in rat dorsal raphe in the slice preparation maintained at $37^{\circ} \mathrm{C}$. The singleelectrode voltage-clamp method was used to measure membrane currents at potentials more negative than rest $(-60$ $\mathrm{mV})$. Three types of inward rectification were observed: 2 in the absence of any drugs and the third induced by 5-HT1 and GABA-B receptor agonists. In the absence of any drugs, an inward current activated over 1-2 sec when the membrane potential was stepped to potentials more negative than $-70 \mathrm{mV}$. This current was blocked by cesium $(2 \mathrm{~mm})$ and resembles $I_{Q}$ or $I_{\mathrm{H}}$. A second inward current $\left(I_{\mathrm{R}}\right)$ occurred at membrane potentials near the potassium equilibrium potential $\left(E_{\mathrm{K}}\right)$. This inward current activated within the settling time of the clamp and was abolished by both barium (10$100 \mu \mathrm{M})$ and cesium (2 mM). 5-HT1 agonists activated a potassium conductance that hyperpolarized the cells at rest. This potassium conductance was about $2 \mathrm{nS}$ at $-60 \mathrm{mV}$ and increased linearly with membrane hyperpolarization to about $4 \mathrm{nS}$ at $-120 \mathrm{mV}$. Baclofen activated a potassium conductance identical in amplitude and voltage dependence to that induced by 5-HT1 agonists. Both the baclofen- and 5-HTinduced currents were nearly abolished in animals pretreated with pertussis toxin. The results indicate that a common potassium conductance is increased by 5-HT acting on 5-HT1 receptors and baclofen acting on GABA-B receptors. This potassium conductance rectifies inwardly and is distinct from the $Q$-current. The ligand-activated potassium conductance also differs from the other form of inward rectification $\left(I_{18}\right)$ in its voltage dependence and sensitivity to pertussis toxin.

The dorsal raphe nucleus, the largest group of 5-hydroxytryptamine (5-HT)-containing neurons in the brain, is found in the rat at the border of the pons and mesencephalon in the midline between the medial longitudinal fasciculi and the aqueduct (Steinbusch, 1981; Paxinos and Watson, 1982). The nucleus contains cells of at least 2 morphologically and physiologically defined subtypes (Aghajanian et al., 1978; Diaz-Cintra et al., 1981; Descarries et al., 1982; Park, 1987). The largest subgroup of neurons contain 5-HT, and the firing rate of these neurons is decreased by 5-HT (Aghajanian et al., 1972; Vandermaelen and Aghajanian, 1983). The decrease in firing rate by 5 -HT was brought about by a membrane hyperpolarization through an increased conductance to potassium ions (Aghajanian and La-

\footnotetext{
Received Nov. 9, 1987; revised Jan. 4, 1988; accepted Jan. 8, 1988.

This work was supported by U.S. Department of Health Services Grant DA04523. Correspondence should be addressed to J. T. Williams, Vollum Institute, Oregon Health Sciences University, 3181 SW Sam Jackson Park Road, Portland, OR 97201.

Copyright (C) 1988 Society for Neuroscience $0270-6474 / 88 / 093499-08 \$ 02.00 / 0$
}

koski, 1984). In addition, agents that release 5-HT such as amphetamine or block its reuptake such as cocaine also decrease the firing rate of these neurons (Sheard et al., 1972; Gallager and Aghajanian, 1976). In the slice preparation, electrical stimulation in the area of the dorsal raphe evokes an inhibitory synaptic potential that reverses at the potassium equilibrium potential (Yoshimura and Higashi, 1985). This synaptic potential is prolonged by imipramine and blocked by agents that descrease 5-HT-induced hyperpolarizations, and it is therefore considered to result from the release of 5-HT.

In the present investigation, membrane currents of 5-HT responsive dorsal raphe neurons were studied in the potential range from rest $(-60 \mathrm{mV})$ to $-130 \mathrm{mV}$. The purpose of this study was to characterize the conductance(s) determining the properties of these neurons at rest and at potentials negative to rest. The 5-H l-induced potassium conductance was studied over the same potential range in order to identify this ligandactivatcd potassium conductance. Some of the results have been reported in abstract form (Williams, 1987).

\section{Materials and Methods}

Intracellular recordings were made from dorsal raphe cells in the slice preparation made from rat pons-mesencephalon. With the exception of the slice chosen, the methods employed were identical to those previously published for recording from locus coeruleus (Williams et al., 1984). Briefly, slices $(300 \mu \mathrm{m})$ were cut in a vibratome in cold $\left(4^{\circ} \mathrm{C}\right)$ physiological saline. Slices were taken from the level of the decussation of the cerebellar peduncle or at the level where the aqueduct begins to open to the fourth ventricle. At least two $300 \mu \mathrm{m}$ slices containing dorsal raphe could be taken from each animal for recording. A single slice was placed in a tissue bath through which flowed physiological saline $(1.5$ $\mathrm{ml} / \mathrm{min}$ ) at $37^{\circ} \mathrm{C}$. The content of the physiological saline solution was as follows (mM): $\mathrm{NaCl}, 126 ; \mathrm{KCl}, 2.5 ; \mathrm{NaH}_{2} \mathrm{PO}_{4}, 1.2 ; \mathrm{MgCl}_{2}, 1.2 ; \mathrm{CaCl}_{2}$ 2.4 ; glucose, $11 ; \mathrm{NaHCO}_{3}, 25$; the solution was gassed with $95 \% \mathrm{O}_{2} / 5 \%$ $\mathrm{CO}_{2}$ at $37^{\circ} \mathrm{C}$.

The area of the dorsal raphe was visible in the slice preparation as a relatively translucent area in the midline between the medial longitudinal fasciculi extending dorsally toward the aqueduct. Neurons were penetrated with glass microelectrodes filled with potassium chloride ( 2 M) having a resistance of 40-80 M $\Omega$. Membrane currents were recorded with a single-electrode voltage-clamp amplifier (Axoclamp 2A) using switching frequencies between 2.5 and $4.5 \mathrm{kHz}$. The switching frequency and amount of capacitance compensation were set at the beginning of the experiment, and the potential at the headstage was monitored continuously with a separate oscilloscope. The settling time of the clamp following a $10 \mathrm{mV}$ step was typically $3-5 \mathrm{msec}$. Steady-state currentvoltage plots were constructed using 2 methods: Currents were measured following voltage steps to various potentials after all transient currents ceased (usually 1-2 sec); current-voltage plots were also constructed directly on an $x-y$ plotter using a slow depolarizing ramp potential (from -130 to $-40 \mathrm{mV})$. The speed of the $\operatorname{ramp}(1 \mathrm{mV} / \mathrm{sec})$ was sufficiently slow to give the same current as a 2 sec step. Slope conductance was measured in portions of the $I-V$ curve that were linear over a $10-15$ $\mathrm{mV}$ potential range. 


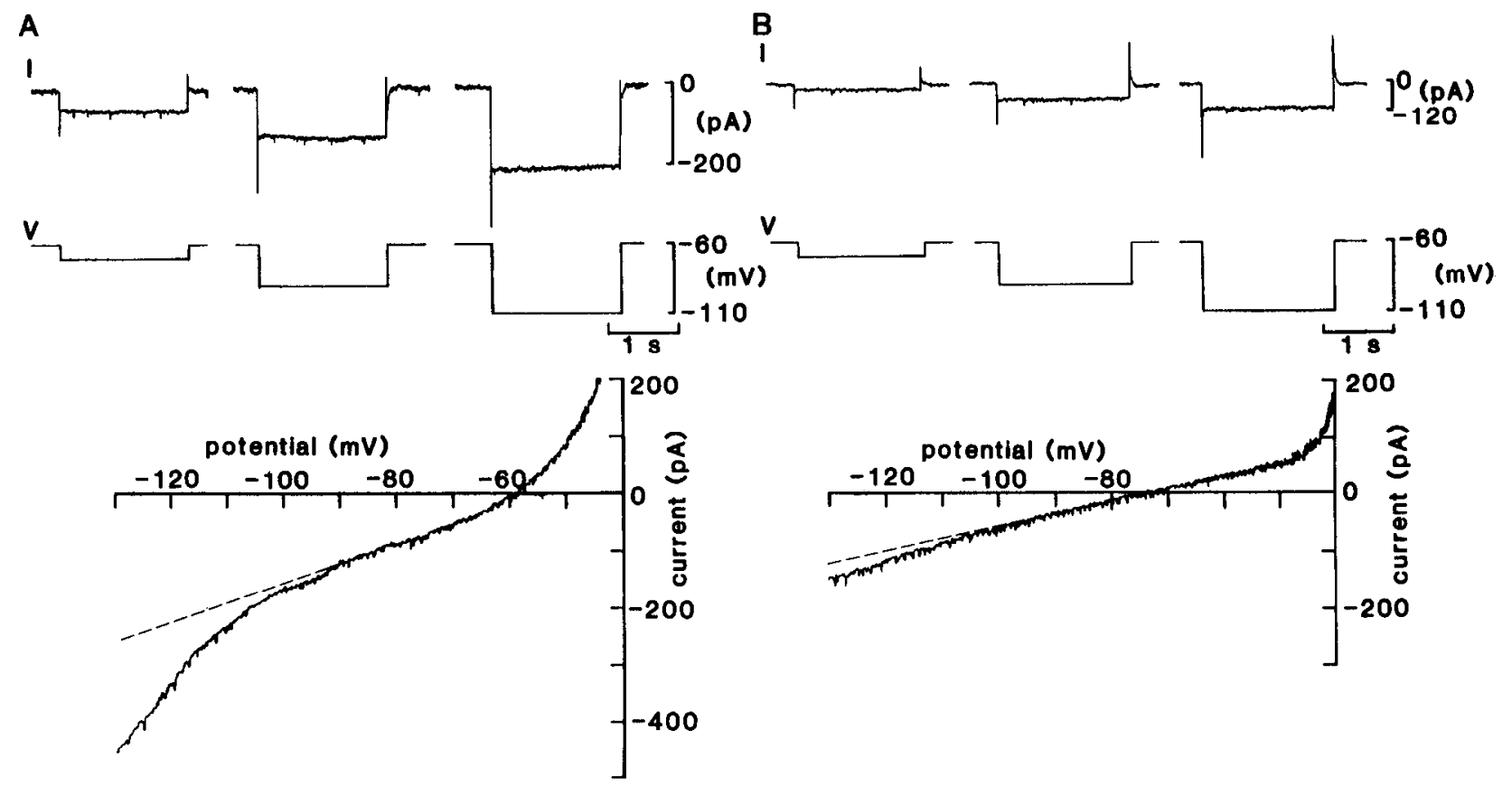

Figure 1. Current-voltage relationships of 2 dorsal raphe neurons. Top traces, Voltage steps $(10,30$, and $50 \mathrm{mV})$ were applied from a holding potential of $-60 \mathrm{mV}$ and the resultant currents were measured. Bottom, Current-voltage plots obtained by slow ramp depolarization from - 130 to about $-40 \mathrm{mV}$. The conductance in the cell illustrated in $A$ is dependent on the membrane potential, being higher at potentials more negative than about $-100 \mathrm{mV}$. The neuron in $B$ has a low conductance, which was almost linear with membrane potential. $A$ and $B$ represent the extremes in conductance measured between different cells in the dorsal raphe. Dashed line was drawn by eye from the portion of the $I-V$ plot between -60 and $-80 \mathrm{mV}$.

Injections of pertussis toxin (List Biochemicals) were made intracerebroventricularly (icv) into the lateral ventricle (bregma $-0.6 \mathrm{~mm}$ P, 2.0 $\mathrm{mm} \mathrm{L}, 4.5 \mathrm{~mm} \mathrm{~V}$, incisor bar +5; Paxinos and Watson, 1982) of rats anesthetized with pentobarbital $(65 \mathrm{mg} / \mathrm{kg}$, i.p.). Rats were allowed to recover and were used for experiments 3-4 d after the injection.

Drugs and solutions containing different ionic content were applied by superfusion. Drugs and salts used included 5 -carboxamidotryptamine (5-CT; gift from Glaxo), ( \pm )-2-dipropylamino-8-hydroxy-1,2,3,4tetrahydronaphthalene $\mathrm{HBr}$ (8OH-DPAT; Research Biochemicals Inc.), 5-hydroxytryptamine (5-HT; Sigma), spiperone (Research Biochemicals Inc.), baclofen (gift from Ciba-Geigy). Numerical data are presented as means \pm SEM.

\section{Results}

At least 2 electrophysiologically distinct neuronal cell types have been described in slices of dorsal raphe, those which fire rapidly and are insensitive to 5-HT and those which are hyperpolarized by 5-HT (Yoshimura and Higashi, 1985). In the present study, all cells were tested with $5-\mathrm{CT}(100 \mathrm{~nm})$. Only results from cells that were hyperpolarized by $5-\mathrm{CT}(95 \%)$ are reported here.

\section{Table 1. Slope conductance of neurons in 2 potential ranges in} various conditions

\begin{tabular}{llr} 
& \multicolumn{2}{l}{ Slope conductance $(\mathrm{nS})$} \\
\cline { 2 - 3 } $\begin{array}{l}\text { Extracellular potassium } \\
(\mathrm{mM})\end{array}$ & $-60 \mathrm{to}$ & \multicolumn{1}{l}{$-110 \mathrm{to}$} \\
\hline 2.5 & $4.5 \pm 0.3(38)$ & $6.2 \pm 0.4(30)$ \\
6.5 & $6.1 \pm 0.5(13)$ & $10.0 \pm 1.7(10)$ \\
10.5 & $7.7 \pm 0.7(10)$ & $12.1 \pm 1.2(10)$ \\
$10.5+\mathrm{BaCl}_{2}(100 \mu \mathrm{M})$ & $6.2 \pm 0.7(6)$ & $5.6 \pm 1.1(6)$ \\
$10.5+\mathrm{BaCl}_{2}+\mathrm{CsCl}(2 \mathrm{mM})$ & $4.8 \pm 1.0(4)$ & $3.4 \pm 0.7(4)$ \\
\hline
\end{tabular}

\section{Inward rectification of the cell membrane}

The steady-state current-voltage relationship between -130 and $-50 \mathrm{mV}$ was not linear (Fig. 1). The slope of the steady-state current-voltage line increased progressively as the membrane potential was made more negative. The slope conductance between -70 and $-80 \mathrm{mV}$ was $4.5 \pm 0.3 \mathrm{nS}(n=38)$ and increased to $6.3 \pm 0.4 \mathrm{nS}(n=30)$ when measured between -110 and $-130 \mathrm{mV}$. There were 2 components that accounted for the observed deviation from an ohmic (linear) conductance at hyperpolarized potentials: an "instantaneous" ( $<5-7 \mathrm{msec}$ ) increase in current and a slowly activating inward component that was fully activated in $0.5-1 \mathrm{sec}$ (slow inward current) (Figs. 14). All cells exhibited this nonlinear current-voltage relationship. The 2 current-voltage plots in Figure 1 illustrate the extremes of the cells encountered.

The inward rectification was always more apparent in solutions of higher potassium ion content. Such solutions depolarized and increased the conductance of cells (Fig. 2, Table 1). Both instantaneous and steady-state currents measured during hyperpolarizing voltage steps from a holding potential of -60 $\mathrm{mV}$ were increased. Most of the increase in conductance in highpotassium solutions (80-90\%) camc about through an increase in the instantaneous conductance (Fig. 2). There was also an increase in the amplitude of the slow inward current (Fig. 2, inset). This current was often just large enough to detect in 2.5 mM potassium but was increased to measurable values in highpotassium solutions (compare Figs. 1 and 2).

Superfusion with a solution containing barium $(10-100 \mu \mathrm{M})$ often caused a small membrane depolarization and a decrease in membrane conductance. Barium most effectively decreased the cell conductance at potentials negative to $E_{\mathrm{K}}$ but had little action in the potential range between rest and about $10 \mathrm{mV}$ less 


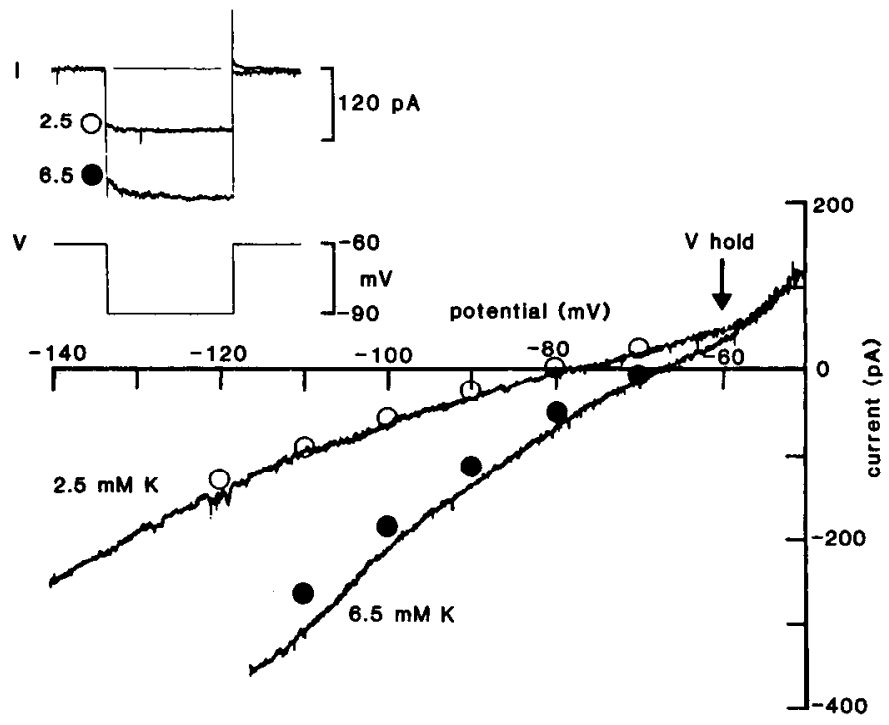

Figure 2. High potassium increases the instantaneous and steady-state conductance. The circles indicate the "instantaneous" current that follows a $1 \mathrm{sec}$ voltage step from a holding potential of $-60 \mathrm{mV}$ (see inset). In this and other current-voltage plots, the arrow indicates the holding potential. Solid lines are the steady-state current-voltage plots from slow ramp depolarizations. Holding current traces have been superimposed for comparison of the instantaneous and steady-state currents.

negative than $E_{\mathrm{K}}$ (Figs. 3, 5; Table 1). The instantaneous current was decreased during the superfusion with $\mathrm{BaCl}_{2}(100 \mu \mathrm{M})$, whereas the slow inward current was either not affected or increased by barium (Figs. 3, 4). The barium (100 $\mu \mathrm{M})$-induccd conductance decrease was larger in experiments in which the conductance of the cell had been increased by high-potassium solutions. Such an action of barium suggests that it is blocking an inwardly rectifying potassium current $\left(I_{\mathrm{IR}}\right.$; Hille, 1984; Williams et al., 1988).

Superfusion of a solution containing $\mathrm{CsCl}(2 \mathrm{~mm})$ also caused a membrane depolarization with a fall in conductance. In contrast to the action of barium, cesium decreased both the instantaneous and the slow inward currents. However, in the presence of barium, cesium caused no further decrease in the instantaneous current (Fig. 4), nor was the steady-state conductance between -50 and $-70 \mathrm{mV}$ affected by cesium (Table 1). With barium present, the decrease in membrane conductance caused by cesium could be almost entirely accounted for by the blockade of the slow inward current (Fig. 5C). In the presence of barium, the cesium-sensitive current occurred at potentials negative to $-70 \mathrm{mV}$ and was independent of the potassium concentration. The slow inward current therefore resembles the Q-current described in many tissues (see Discussion).

\section{Activation of $5-H T 1$ receptors}

We observed that 5-HT agonists hyperpolarize dorsal raphe neurons by increasing the conductance to potassium ions, as has been reported by others (Aghajanian and Lakoski, 1984; Yoshimura and Higashi, 1985). The amplitude of the hyperpolarization was dependent on the concentration of agonist applied (Fig. 6). The concentration response curves to 5-CT and to $8 \mathrm{OH}$-DPAT were similar, having an $\mathrm{EC}_{50}$ of $10-20 \mathrm{nM}$ (Fig. 6). More than 1000-fold greater concentration of 5-HT was required to cause equivalent hyperpolarizations. The maximum hyperpolarization induced by either 5-CT or 8OH-DPAT was
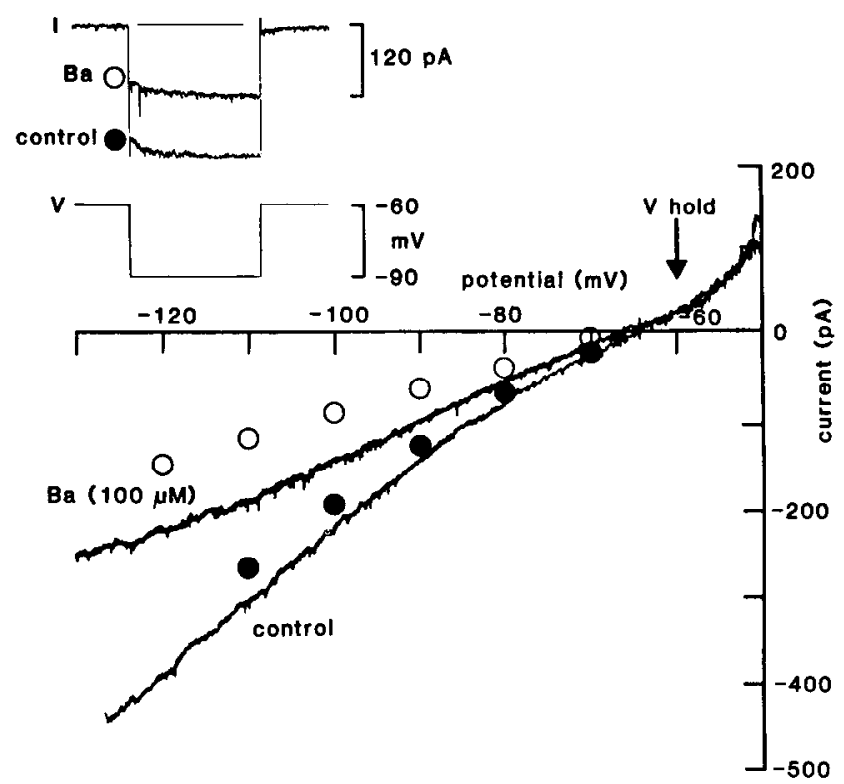

Figure 3. Barium decreases the instantaneous and steady-state conductance and does not block slow inward current. Closed circles indicate the "instantaneous" current (see inset) in control. Open circles indicate the instantaneous current after superfusion with $\mathrm{Ba}(100 \mu \mathrm{M})$. Solid lines are the steady-state current-voltage plots obtained from slow ramp depolarizations in control and in $\mathrm{Ba}(100 \mu \mathrm{M})$. The entire experiment was carried out in $6.5 \mathrm{~mm}$ potassium.

16-20 $\mathrm{mV}$. The hyperpolarization to 5-CT was antagonized by spiperone $(1 \mu \mathrm{M})$. The $K_{d}$ for spiperone was estimated to be 28.5 $\pm 9.3 \mathrm{~nm}(n=7$; range, $8.5-81 \mathrm{~nm})$ based on a single parallel shift in the 5-CT concentration response curve caused by spiperone (1 $\mu \mathrm{M})$ (Kosterlitz and Watt, 1968).

\section{Inward rectification of 5-HT-activated potassium conductance}

Slow ramp depolarizations were used to plot the current-voltage relationship in the absence and presence of 5-CT. $I_{5-\mathrm{CT}}$ was determined by taking the difference in the current measured at 10 $\mathrm{mV}$ intervals from -130 to $-50 \mathrm{mV}$ (Fig. $7 A$ ). That current $\left(I_{5 \text {-CI }}\right)$ was plotted as a function of membrane potential (Fig.

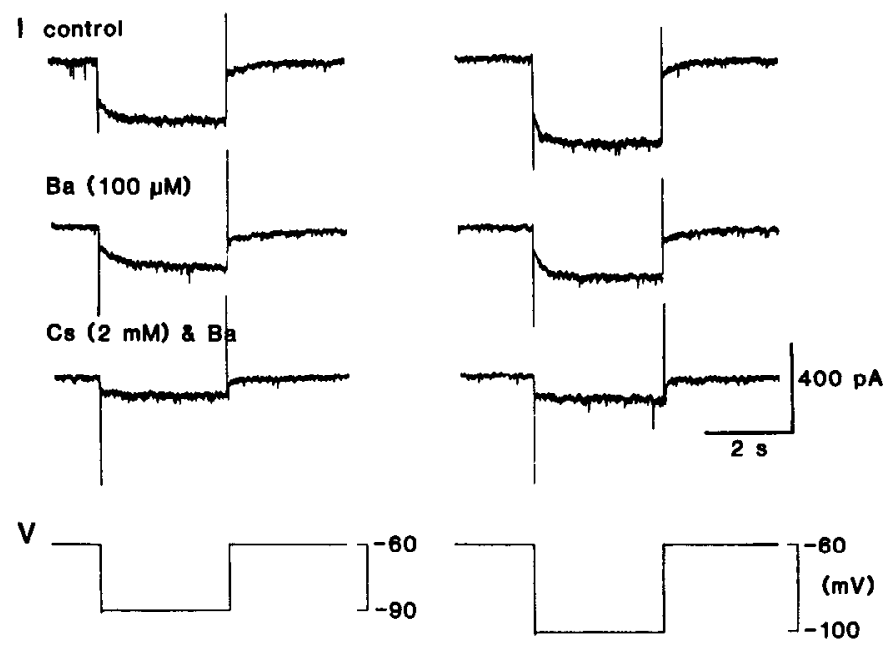

Figure 4. Cesium blocks the slow inward current $\left(I_{\mathrm{O}}\right)$. Top, Current traces in control, in $\mathrm{Ba}(100 \mu \mathrm{M})$, and in Cs $(2 \mathrm{mM})$ plus $\mathrm{Ba}(100 \mu \mathrm{M})$. Bottom, Voltage steps of 30 and $40 \mathrm{mV}$ from a holding potential of $-60 \mathrm{mV}$. The entire experiment was carried out in $10.5 \mathrm{~mm}$ potassium. 

A. control
B. $K(10.5 \mathrm{mM})$
C. $K(10.5 \mathrm{mM}) \& \mathrm{Ba}(100 \mu \mathrm{M})$

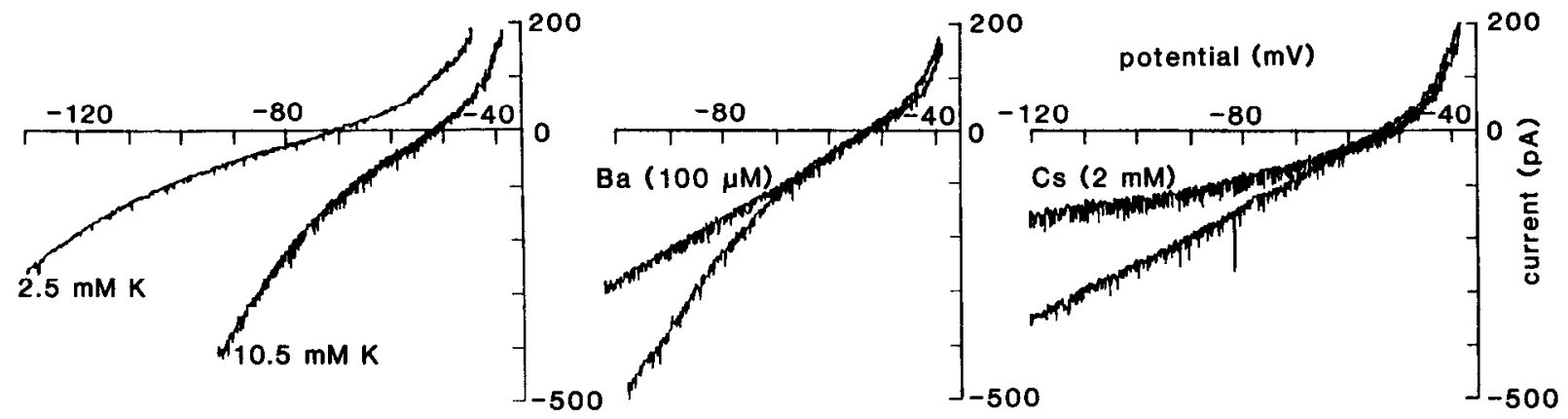

Figure 5. Voltage-dependent blockade of steady-state currents by barium and cesium. Steady-state current-voltage plots obtained from a slow ramp depolarization from a single cell. $A$, High-potassium solution $(10.5 \mathrm{~mm})$ increased the conductance of the cell and shifted the potential at the zero current level. $B$, Addition of $\mathrm{BaCl}_{2}(100 \mu \mathrm{M})$ decreased the steady-state conductance negative to $-70 \mathrm{mV}$. $C$, Addition of CsCl (2 mM) to the barium-containing solution further decreased the conductance at potentials negative to $-65 \mathrm{mV}$.

$7 B$ ). The reversal potential in $2.5 \mathrm{~mm}$ potassium was -101.7 $\pm 2.0 \mathrm{mV}(n=7)$. This value shifted to $-78.0 \pm 2.3 \mathrm{mV}(n=$ 6) in $6.5 \mathrm{~mm}$ potassium, and to $-66.7 \pm 4.3 \mathrm{mV}$ in $10.5 \mathrm{~mm}$ potassium $(n=5)$. The shifts in reversal potential with the changes in extracellular potassium were predicted by the Nernst equation (Fig. $8 \mathrm{C}$ ). The conductance increase caused by 5-CT $\left(G_{5 \mathrm{CT}}\right)$ was plotted as a function of membrane potential for an individual cell (Fig. $8 B$ ) and among cells (Fig. 8D). $G_{5 C T}$ increased with membrane hyperpolarization from $-50 \mathrm{mV}$. In $2.5 \mathrm{~mm}$ potassium, $G_{5 \mathrm{CT}}$ was $2.2 \pm 0.3 \mathrm{nS}(n=7)$ at $-50 \mathrm{mV}$; this increased $1.8 \pm 0.09$-fold $(n=7)$ with membrane hyperpolarization to $-120 \mathrm{mV}$. In Figure $8 D, G_{\mathrm{sCT}}$ increased continuously with membrane hyperpolarization from -50 to -130 $\mathrm{mV}$. The dependence of $G_{5 \mathrm{CT}}$ on membrane potential was more evident in high-potassium solutions.
In high-potassium solutions, the slope of the $G_{5 \mathrm{CT}}$-membrane potential plot was greater than in control (Fig. 8). In addition, $G_{\text {SCT }}$ increased at a given membrane potential when the potassium ion concentration was increased. In $2.5 \mathrm{~mm}$ potassium, $G_{5 \mathrm{CT}}$ was $2.2 \pm 0.3 \mathrm{nS}(n=7)$ at $-60 \mathrm{mV}$; it increased to 3.3 $\pm 0.7 \mathrm{nS}(n=6)$ and $5.0 \pm 1.6 \mathrm{nS}(n=5)$ in 6.5 and $10.5 \mathrm{~mm}$ potassium, respectively. The results from a single cell are shown in Figure $8 B$ and are summarized among cells in Figure $8 D$.

The increase in potassium conductance caused by 5-CT when stepping from rest to potentials more negative than $E_{\mathrm{K}}$ occurred within the settling time of the single electrode voltage clamp distinguishing this current from $I_{\mathrm{Q}}$. In addition, the Q-current was not affected by superfusion with 5-CT. The rectification of the 5-CT current was blocked by superfusion with $\mathrm{BaCl}_{2}(100$ $\mu \mathrm{M})$. In the presence of barium, 5-CT still caused an inward

A

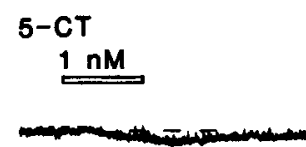

Baclofen

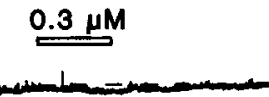

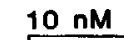

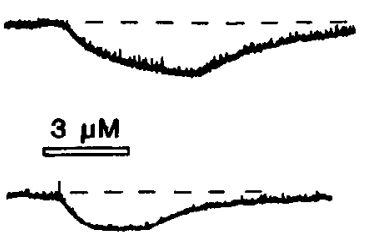

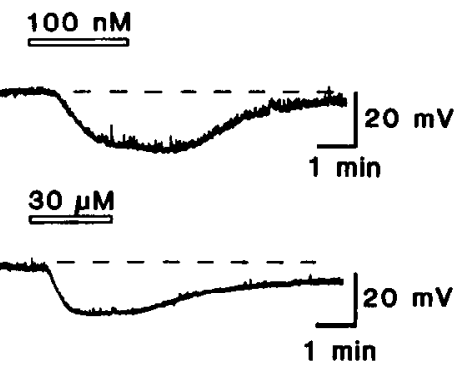

B

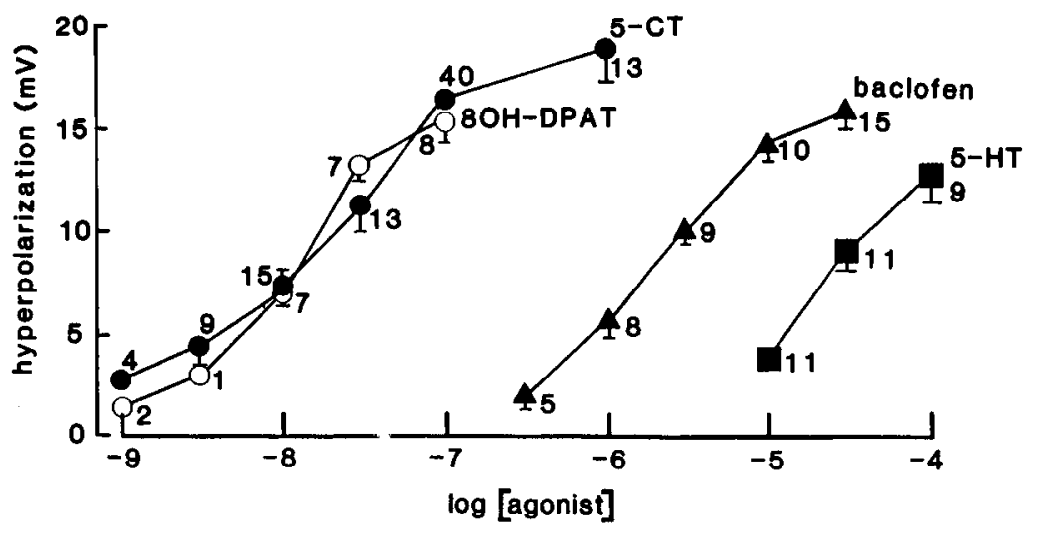

Figure 6. 5-HT agonists and baclofen produce a hyperpolarization that is related to the concentration applied. $A$, Voltage recordings from 2 neurons during superfusion of 5-CT (top) and baclofen (bottom). The superfusion solution was changed during the period indicated by the bar above the trace. $B$, Dose-response relationships taken from many cells for 5-CT (solid circles), 8-OH-DPAT (open circles), 5-HT (solid squares), and baclofen (solid triangles). The numbers beside each point indicate the number of cells tested at that concentration. 
B

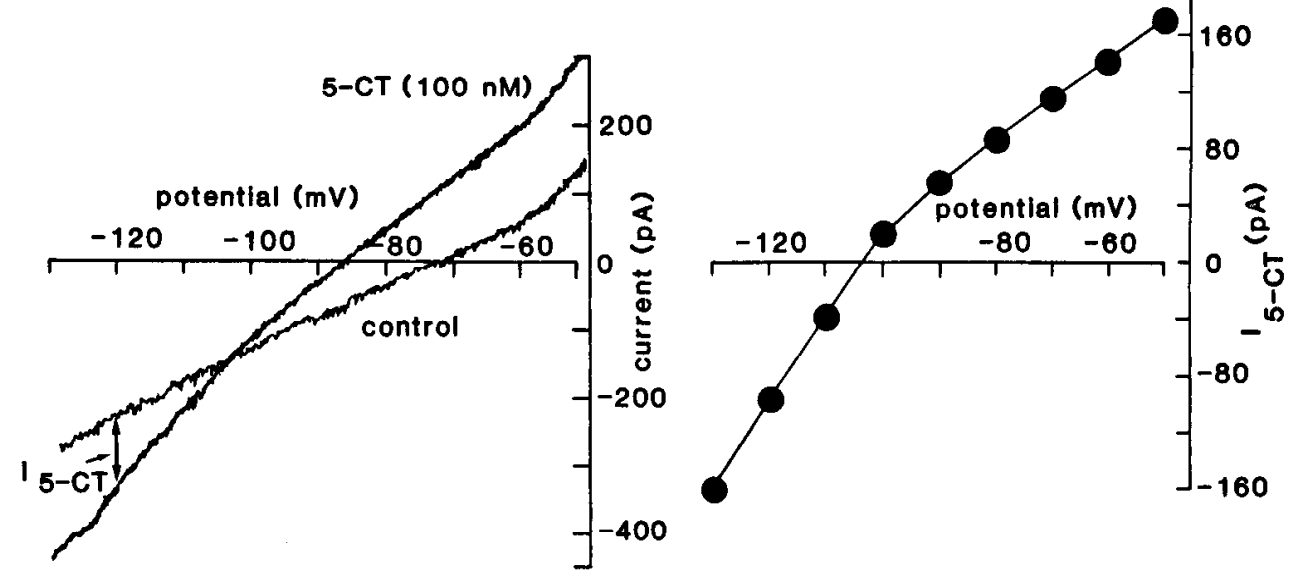

Figure 7. 5-CT hyperpolarizes dorsal raphe neurons by increasing a conductance that reverses at $-105 \mathrm{mV}$. A, Two superimposed current-voltage plots in the presence and absence of 5-CT (100 nM). The difference between the plots $\left(I_{5-\mathrm{CT}}\right)$ was measured at $10 \mathrm{mV}$ intervals. $B, I_{\text {S-CT }}$ is plotted agonist membrane potential. The reversal potential was about $-105 \mathrm{mV}$, and the slope of the line increased as the membrane potential was shifted to more negative potentials.

A

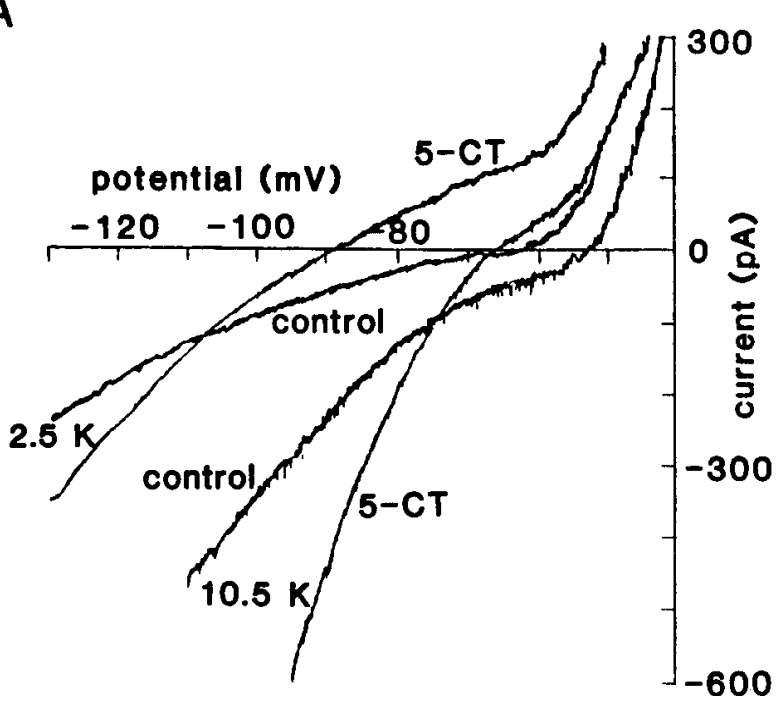

B
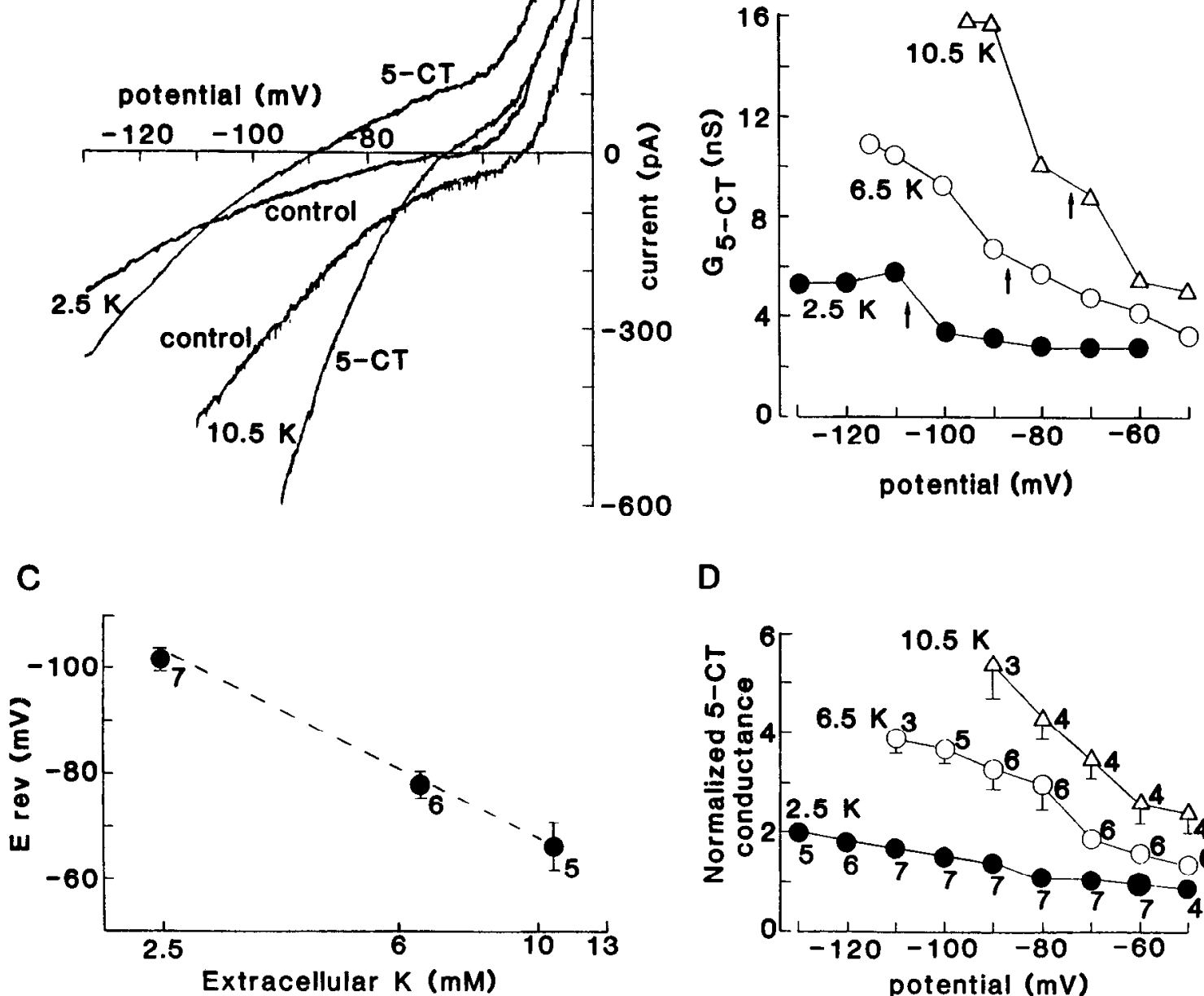

D

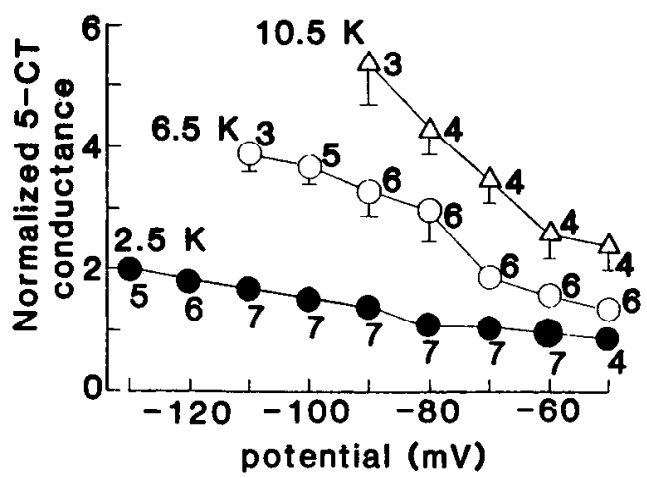

Figure 8. The 5-HT1-receptor-induced increase in potassium conductance rectifies inwardly. $A$ Steady-state current-voltage plots in the presence and absence of 5-CT in 2 concentrations of potassium. The reversal potential shifts to a less negative value in high potassium. $B, G_{5-\mathrm{cr}}$ plotted as a function of membrane potential. $G_{5-\mathrm{CT}}$ increased as the membrane potential was made more negative and the slope increased in high potassium concentrations. $C$, The reversal potential of the 5-CT current plotted against the external potassium concentration. Filled circles indicate the mean of the experimental points (slope $-57, r=0.9996$ ). The dashed line was determined from the Nernst equation, where the internal potassium content was fixed at $135 \mathrm{~mm}$. $D$, The 5 -CT conductance was normalized to the value obtained at $-60 \mathrm{mV}$ in $2.5 \mathrm{~mm}$ potassium for cach cell. The normalized values were averaged among cells and plotted as a function of membrane potential. 


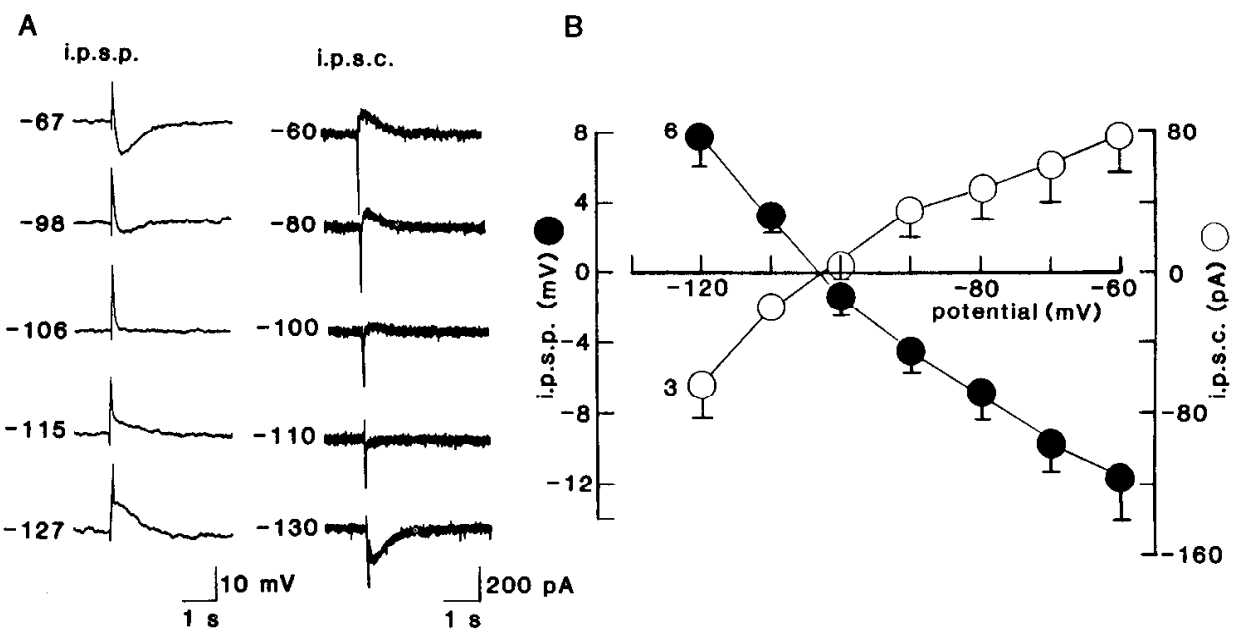

Figure 9. Inhibitory synaptic potentials are caused by a potassium conductance that rectifies inwardly. $A$, Potential (left) and current (right) recordings from a single neuron. The membrane potential was held at various levels, indicated at the left of the trace, and a single electrical stimulus was used to evoke synaptic potentials. The polarity of the i.p.s.p. and i.p.s.c. changed as the membrane potential was made more negative. $B$, The amplitude of the i.p.s.p. and i.p.s.c. from several cells at various membrane potentials was averaged and plotted as a function of membrane potential. The time following the stimulus at which the i.p.s.p. reached its peak when evoked from rest $(-60 \mathrm{mV}, 100-200 \mathrm{msec})$ was used to determine the i.p.s.p. amplitude at other potentials. The change in amplitude of both the i.p.s.p. and i.p.s.c. was a nonlinear function of membrane potential, increasing in slope with membrane hyperpolarization.

current at potentials negative to $E_{\mathrm{K}}$. That is, $G_{\mathrm{SCT}}$ was no longer potential dependent, heing about $2 \mathrm{nS}$ at $-60 \mathrm{mV}$ and the same at $-120 \mathrm{mV}$.

\section{Rectification of conductance evoked by synaptic release of 5-HT}

We also studied the voltage dependence of the potassium conductance increased by synaptically released 5-HT. An electrically evoked inhibitory postsynaptic potential (i.p.s.p.) thought to be mediated by 5-HT has previously been described in the dorsal raphe (Yoshimura and Higashi, 1985). The i.p.s.p.'s were 5-20 $\mathrm{mV}$ in amplitude, $1-2 \mathrm{sec}$ in duration and reversed at the potassium equilibrium potential (Yoshimura and Higashi, 1985). The voltage dependence of the i.p.s.p. and inhibitory postsynaptic currents (i.p.s.c.s) were determined under current and voltage clamp, respectively, by evoking synaptic potentials while holding the membrane potential levels ranging from -60 to $-130 \mathrm{mV}$ (Fig. 9). The amplitudes of the i.p.s.p. and i.p.s.c. were measured at many different potentials and plotted as a

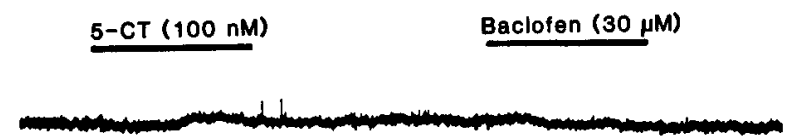

NA $(10 \mu M)$

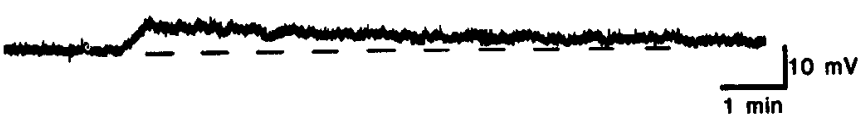

Figure 10. Pertussis toxin treatment blocks the hyperpolarization induced by 5 -CT and baclofen but leaves the depolarization induced by noradrenaline. Recording of membrane potential $(-60 \mathrm{mV})$ in a cell taken from a rat pretreated with pertussis toxin. Superfusion of 5-CT $(100 \mathrm{nM})$ and baclofen $(30 \mu \mathrm{M})$ had no effect on membrane potential. In the same cell, noradrenaline $(30 \mu \mathrm{M})$ caused a depolarization of about $8 \mathrm{mV}$. function of membrane potential. Both the i.p.s.c. and i.p.s.p. were nonlinear with membrane potential (Fig. 9). The slope of the i.p.s.c.(i.p.s.p.)/potential plots increased as the membrane potential was moved to more negative potentials. The rectification of the synaptically evoked outward current was comparable with that of the exogenously applied 5-CT (compare Figs. $8,9)$.

\section{Baclofen increased potassium conductance}

The GABA-B agonist baclofen induced a membrane hyperpolarization in dorsal raphe neurons (Fig. 6). The $\mathrm{EC}_{50}$ was about $2 \mu \mathrm{M}$, and the peak amplitude was $14.9 \pm 0.9 \mathrm{mV}(n=15)$. In voltage-clamp conditions, superfusion with $30 \mu \mathrm{M}$ baclofen caused an outward current with a voltage dependence identical to that caused by 5-CT. In addition, the outward current induced by baclofen $(30 \mu \mathrm{M})$ was not further increased by the addition of 5-CT $(100 \mathrm{nM})$ to the baclofen-containing solution $(n=3)$.

\section{Agonist-induced potassium conductance is blocked by pertussis toxin}

In animals injected (icv) with pertussis toxin 3-4 d prior to the experiment, the action of 5-CT (1-3 $\mu \mathrm{M})$ was reduced to $3.1 \pm$ $0.7 \mathrm{mV}(n=20)$. The hyperpolarization induced by baclofen $(30 \mu \mathrm{M})$ was also reduced to $1.8 \pm 0.6 \mathrm{mV}(n=19)$. In these experiments, no slow i.p.s.p.s could be evoked $(n=5)$. Despite the absence of observable hyperpolarizing response to either 5-HT or baclofen, the properties of these cells were qualitatively similar to those from untreated animals. Their resting potential, slope conductance $(4.3 \pm 0.5 \mathrm{nS}$ between -60 and $-80 \mathrm{mV}$; see Table 1), and action potential waveform were indistinguishable from control. All cells tested with noradrenaline (1-3 $\mu \mathrm{M})$ or phenylephrine (1-3 $\mu \mathrm{M}$ ) were depolarized from rest (by 7.4 $\pm 0.9 \mathrm{mV}, n=12$ ), indicating that the $\alpha_{1}$-adrenoceptor-activated conductance was left intact. The inward rectification of the membrane in the absence of drugs in pertussis toxin-treated animals did not differ from controls. The increase in the slope conductance going from -60 to $-110 \mathrm{mV}$ was $1.4 \pm 0.08$-fold 
$(n=20)$ in controls and $1.5 \pm 0.15$-fold in pertussis toxin-treated animals $(n=14)$.

\section{Discussion}

The results indicate that there are 3 forms of inward rectification at potentials negative to rest in the neurons of the dorsal raphe: $I_{\mathrm{Q}}, I_{\mathrm{IR}}$, and $I_{5-\mathrm{HT}}\left(I_{\text {baclofen }}\right)$. At potentials negative to $-70 \mathrm{mV}$, a slowly activating ( $300 \mathrm{msec}-1 \mathrm{sec}$ ), noninactivating inward current occurred. The amplitude of this inward current was increased in high-potassium solutions and blocked by extracellular cesium ( $2 \mathrm{~mm}$ ). The insensitivity of this current to barium, its voltage dependence and time course of activation indicate that this current is similar to $I_{\mathrm{H}}$ or $I_{\mathrm{Q}}$, which has becn described in detail in other neurons and in smooth muscle (Mayer and Westbrook, 1983; Crepel and Penit-Sorea, 1986; Benham et al., 1987). There was some variation among different neurons in the amount of rectification observed, especially under normal recording conditions $\left(2.5 \mathrm{~mm} \mathrm{~K}^{+}\right)$. In normal extracellular potassium concentrations, this conductance accounts for only a minor proportion of the lotal membrane conductance of dorsal raphe neurons, even at potentials negative to $-70 \mathrm{mV}$. In certain conditions, however, the proportion of the total membrane conductance attributable to the Q-current could be increased, for example, when other potassium conductances were decreased (Fig. 6C). The role that this conductance plays in determining the activity of dorsal raphe neurons may be enhanced directly by neurotransmitters, as has been found in the heart (Brown and DiFrancesco, 1980), or with the inactivation of certain potassium conductances by neurotransmitters. For example, noradrenaline has been reported to decrease at least 2 potassium currents in dorsal raphe neurons (Aghajanian, 1985; Yoshimura and Higashi, 1985).

Dorsal raphe neurons also exhibit potassium channel inward rectification similar to that described in detail in skeletal muscle (Katz, 1949; cf. Hille, 1984) and since identified in mammalian CNS (Constanti and Galvin, 1983; Osmanovic and Shefner, 1987; Williams et al., 1988). This conductance is activated within $5 \mathrm{msec}$ following a step hyperpolarization to potentials negative to $-100 \mathrm{mV}$ (in $2.5 \mathrm{~mm} \mathrm{~K}$ ). In high-potassium solutions the amplitude of this rectification increased and the voltage at which it occurred became less negative. This conductance was also selectively blocked by low concentrations of barium. The voltage dependence of $I_{\mathrm{IR}}$ in the present study is best illustrated in Figures 3 and $4 B$, where the barium-sensitive component of the $I-V$ plot $\left(I_{\mathrm{IR}}\right)$ centers around $E_{\mathrm{K}}$. Barium had little or no effect on the membrane conductance at potentials near rest.

The 5-HT-induced conductance increase to potassium ions in dorsal raphe neurons has not been distinguished from the various types of potassium conductance in the cells (Aghajanian and Lakoski, 1984; Yoshimura and Higashi, 1985). The results of the present study indicate that $I_{5-\mathrm{HT}}$ differs from $I_{\mathrm{IR}}$ in its voltage dependence and its sensitivity to pertussis toxin. $I_{5-\mathrm{HT}}$ was outward at $-50 \mathrm{mV}$ and rectified over a broad potential range $(-50$ to $-130 \mathrm{mV}$; Fig. $8 D$ ). This observation contrasts with that made when measuring the inward rectification of the "resting" membrane, which was not active at $-50 \mathrm{mV}$ and had a steep voltage dependence near $E_{\mathrm{K}}$. It should also be pointed out that the amplitude of the inwardly rectifying current varied widely among cells (Fig. 1), whereas the ligand-activated conductance was independent of the rectification of the resting membrane.

Qualitatively similar observations have been made in the locus coeruleus, where $\mu$-opioid and $\alpha_{2}$-adrenergic receptor activation increased a potassium conductance that also rectified over a wide potential range (North et al., 1987). In the locus coeruleus there was about a 2 -fold increase in the opioid $/ \alpha_{2}$ adrenoceptor conductance going from -60 to $-120 \mathrm{mV}$. Such an increase is similar to that observed in the present study for 5-HT agonists. The similarities between the ligand-activated conductances in the 2 tissues contrast with the comparison of the amplitude of $I_{\mathrm{IR}}$ observed at rest in the 2 tissues. In the locus coeruleus, the inward rectification of the membrane in the absence of drugs resulted in an increase of the slope conductance from $8 \mathrm{nS}$ at $-60 \mathrm{mV}$ to about $24 \mathrm{nS}$ at $-120 \mathrm{mV}$ (Williams et al., 1988). Over a similar potential range, only a 1.5 -fold increase in conductance was found in dorsal raphe neurons (Table 1).

5-HT acting on 5-HT 1 subtype receptors increased a potassium conductance in hippocampus, an action shared by baclofen and blocked with prior treatment with pertussis toxin (Andrade et al., 1986). This action of 5-HT in hippocampus also shows inward rectification (Colino and Halliwell, 1987). We report here identical results in the dorsal raphe. There is an increasing number of ligands acting on a variety of receptors which activate a potassium conductance with 2 common properties: a voltage dependence (inward rectification) and a pertussis toxin-sensitive g-protein linked between the receptor and the potassium channel (North et al., 1987). It seems that this may be a common mechanism for inhibition.

\section{References}

Aghajanian, G. K. (1985) Modulation of a transient outward current in serotonergic neurons by alpha ${ }_{1}$-adrenoceptors. Nature 315 : $501-$ 503.

Aghajanian, G. K., and J. M. Lakoski (1984) Hyperpolarization of serotonin neurons by serotonin and LSD: Studies in brain slices showing increased $\mathrm{K}^{+}$conductance. Brain Res. 305: 181-185.

Aghajanian, G. K., H. J. Haigler, and F. E. Bloom (1972) Lysergic acid diethylamide and serotonin: Direct actions on serotonin-containing neurons in rat brain. Life Sci. 11: 615-622.

Aghajanian, G. K., R. Y. Wang, and J. M. Baraban (1978) Serotoninergic and non-serotoninergic neurons of the dorsal raphe: Reciprocal changes in firing induced by peripheral nerve stimulation. Brain Res. 153: 169-175.

Andrade, R., R. C. Malenka, and R. A. Nicoll (1986) A G protein couples serotonin and $\mathrm{GABA}_{\mathrm{B}}$ receptors to the same channels in hippocampus. Science 234: 1261-1265.

Benham, C. D., T. B. Bolton, J. S. Denbigh, and R. J. Lang (1987) Inward rectification in freshly isolated single smooth muscle cells of the rabbit jejunum. J. Physiol. (Lond.) 383: 461-476.

Brown, H., and D. DiFrancesco (1980) Voltage-clamp investigations of membrane currents underlying pace-maker activity in rabbit sinoatrial node. J. Physiol. (Lond.) 308: 331-351.

Crepel, F., and J. Penit-Soria (1986) Inward rectification and low threshold calcium conductance in rat cerebellar purkinje cells: An in vitro study. J. Physiol. (Lond.) 372: 1-23.

Colino, A., and J. V. Halliwell (1987) Differential modulation of three separate K-conductances in hippocampal CA1 neurons by serotonin. Nature 328: 73-77.

Constanti, A., and M. Galvin (1983) Fast inward-rectifying current accounts for anomalous rectification in olfactory cortex neurons. $J$. Physiol. (Lond.) 385: 153-178.

Descarries, L., K. C. Watkins, S. Garcia, and A. Beaudet (1982) The serotonin neurons in nucleus raphe dorsalis of adult rat: A light and electron microscope radioautographic study. J. Comp. Neurol. 207: 239-254.

Diaz-Cintra, S., L. Cintra, T. Kemper, O. Resnick, and P. J. Morgane (1981) Nucleus raphe dorsalis: A morphometric golgi study in rats of three age groups. Brain Res 207: 1-16.

Gallager, D. W., and G. K. Aghajanian (1976) Inhibition of firing of 
raphe neurons by tryptophan and 5-hydroxytryptophan: Blockade by inhibiting serotonin synthesis with Ro-4-4602. Neuropharmacology 15: $149-156$.

Hille, B. (1984) Ionic Channels of Excitable Membranes, Sinauer, Sunderland, MA.

Katz, B. (1949) Les constantes electriques de la membrane du muscle. Arch. Sci. Physiol. 2: 285-299.

Kosterlitz, H. W., and A. J. Watt (1968) Kinetic parameters of narcotic agonists and antagonists with particular reference to $\mathrm{N}$-allylnoroxymorphine (naloxone). Br. J. Pharmacol. Chemother. 33: 266-276.

Mayer, M. L., and G. L. Westbrook (1983) A voltage-clamp analysis of inward (anomalous) rectification in mouse spinal sensory ganglion neurons. J. Physiol. (Lond.) 340: 19-45.

North, R. A., J. T. Williams, A. Surprenant, and M. J. Christie (1987) $\mu$ and $\delta$ receptors both belong to a family of receptors which couple to a potassium conductance. Proc. Nat. Acad. Sci. USA 84: 54875491.

Osmanovic, S. S., and S. A. Shefner (1987) Anomalous rectification in rat locus coeruleus neurons. Brain Res. 417: 161-166.

Park, M. R. (1987) Intracellular horseradish peroxidase labeling of rapidly firing dorsal raphe projection neurons. Brain Res. 402: 117130.

Paxinos, G., and C. Watson (1982) The Rat Brain in Stereotaxic Coordinates, Academic, New York.
Sheard, M. H., A. Zolovick, and G. K. Aghajanian (1972) Raphe neurons: Effect of tricyclic antidepressant drugs. Brain Res. 43: 690694.

Vandermaelen, C. P., and G. K. Aghajanian (1983) Electrophysiological and pharmacological characterization of serotonergic dorsal raphe neurons recorded extracellularly and intracellularly in rat brain slices. Brain Res. 289: 109-119.

Williams, J. T. (1987) Inwardly rectifying potassium currents induced by $5-\mathrm{HT}$ in dorsal raphe. Neurosci. Soc. Abstr. 13: 1650.

Williams, J. T., R. A. North, S. A. Shefner, S. Nishi, and T. M. Egan (1984) Membrane properties of rat locus coeruleus neurons. Neuroscience 13: 137-156.

Williams, J. T., R. A. North, and T. Tokimasa (1988) Inward rectification of resting and receptor-linked potassium currents in rat locus coeruleus neurons. J. Neurosci. (in press).

Yoshimura, M., and H. Higashi (1985) 5-hydroxylryplamime mediates inhibitory postsynaptic potentials in rat dorsal raphe neurons. Neurosci. Lett. 53: 69-74.

Yoshimura, M., H. Higashi, and S. Nishi (1985) Noradrenaline mediates slow excitatory synaptic potentials in rat dorsal raphe neurons in vitro. Neurosci. Lett. 61: 305-310. 